\title{
Glioblastoma Multiforme: An Overview of Emerging Therapeutic Targets
}

\author{
Olivia G. Taylor ${ }^{1,2 t \neq}$, Joshua S. Brzozowski ${ }^{1,2 t \neq}$ and Kathryn A. Skelding ${ }^{1,2 * \neq}$ \\ ${ }^{1}$ Faculty of Health and Medicine, Priority Research Centre for Cancer Research, Innovation and Translation, School of \\ Biomedical Sciences and Pharmacy, University of Newcastle, Callaghan, NSW, Australia, ${ }^{2}$ Hunter Cancer Research Alliance \\ and Cancer Research Program, Hunter Medical Research Institute, New Lambton Heights, NSW, Australia
}

OPEN ACCESS

Edited by:

Gabi U. Dachs,

University of Otago, Christchurch,

New Zealand

Reviewed by:

Braden C. McFarland,

University of Alabama at Birmingham,

United States

Karishma Rajani,

Mayo Clinic, United States

${ }^{*}$ Correspondence:

Kathryn A. Skelding

kathryn.skelding@newcastle.edu.au

tThese authors have contributed equally to this work

¥ORCID:

Olivia G. Taylor

orcid.org/0000-0002-2850-6551

Joshua S. Brzozowsk

orcid.org/0000-0001-5508-5257

Kathryn A. Skelding

orcid.org/0000-0002-9230-3417t

Specialty section:

This article was submitted to

Cancer Molecular Targets and

Therapeutics,

a section of the journal

Frontiers in Oncology

Received: 23 July 2019 Accepted: 11 September 2019

Published: 26 September 2019

Citation:

Taylor OG, Brzozowski JS and Skelding KA (2019) Glioblastoma Multiforme: An Overview of Emerging

Therapeutic Targets.

Front. Oncol. 9:963.

doi: 10.3389/fonc.2019.00963
Glioblastoma multiforme (GBM) is the most common and aggressive malignant primary brain tumour in humans and has a very poor prognosis. The existing treatments have had limited success in increasing overall survival. Thus, identifying and understanding the key molecule(s) responsible for the malignant phenotype of GBM will yield new potential therapeutic targets. The treatment of brain tumours faces unique challenges, including the presence of the blood brain barrier (BBB), which limits the concentration of drugs that can reach the site of the tumour. Nevertheless, several promising treatments have been shown to cross the BBB and have shown promising pre-clinical results. This review will outline the status of several of these promising targeted therapies.

Keywords: glioblastoma, targeted therapeutics, anti-cancer drugs, brain cancer, immunotherapy

\section{INTRODUCTION}

Glioblastoma multiforme (GBM) is the most common and aggressive primary malignant brain tumour and accounts for $60 \%$ of brain tumours in adults (1). The global incidence of GBM is $<10$ per 100,000 persons (2) and has increased over the last decade (3). GBM patients have a poor prognosis with a 1-year survival rate of $37.2 \%$, a 5 -year survival rate of $5.1 \%$ (4) and a median survival of $\sim 10$ months (5). GBM is divided into three subgroups based on isocitrate dehydrogenase 1 (IDH1) and IDH2 mutation status: IDH-mutant, IDH-wild-type and NOS (not otherwise specified) (6-8). However, despite this classification, the majority of GBM patients receive identical treatments, and few targeted therapies currently exist, contributing to the poor outcomes typically experienced by GBM patients. This review will outline the current treatment options for GBM and discuss some of the more recent developments in targeted therapies being investigated for the treatment of GBM.

\section{CURRENT TREATMENT OPTIONS}

The treatment of brain tumours faces unique challenges, most notably the presence of the blood brain barrier (BBB), a highly selective semipermeable barrier that separates blood from the brain. The $\mathrm{BBB}$ is comprised of the endothelial cells of capillaries, astrocytes surrounding the capillary, and pericytes embedded in the capillary basal lamina. Physiochemical properties including molecular weight, lipophilicity and charge affect the ability of a molecule to cross the BBB (9). The BBB prevents nearly all large molecules ( $>400 \mathrm{Da}$ ) (10) and $\sim 98 \%$ of small molecule drugs from entering the central nervous system (CNS) (11). The current treatment pipeline begins with surgical resection of the tumour, if applicable and safe to do so, followed by radiotherapy and concomitant chemotherapy $(12,13)$. 
The initial therapeutic approach for GBM is surgery, where maximal resection is associated with longer progression-free survival (PFS) and overall survival (OS) (14). Resection is not a curative approach; hence, patients typically undergo radiotherapy and chemotherapy as an adjunct (15). Radiotherapy, at a total dose of $60 \mathrm{~Gy}$, is administered as either primary treatment or following surgery (16), both resulting in improvements to PFS and OS. Concomitant administration of temozolomide [150-200 $\mathrm{mg} / \mathrm{m}^{2} /$ day for 5 days each 28 -days cycle $(12,13)]$, an oral alkylating agent, significantly increases OS in patients with newly diagnosed GBM from 12.1 months with radiotherapy alone to 14.6 months with radiotherapy and temozolomide (13). However, despite this increase in survival with radiotherapy and temozolomide, tumour progression and recurrence typically occur $(17,18)$, due to the development of resistance to temozolomide $(19,20)$. Once GBM recurrence occurs, therapeutic options for patients are limited $(21,22)$. Recently, tumour treating fields (TTFields; Optune), which deliver electric fields to the tumour location to disrupt cancer cell division, have emerged as an FDA-approved treatment for both recurrent and newly diagnosed GBM (23). However, the identification of new targets to facilitate the development of novel targeted therapies is warranted.

\section{EMERGING TARGETED THERAPIES}

GBM is an invasive tumour with hallmarks of neoangiogenesis and intratumour heterogeneity, contributing to the poor prognosis observed (24). A variety of genetic and epigenetic alterations have been identified in GBM that influence patient prognosis (Table 1). Despite this heterogeneity, a large-scale analysis of genetic aberrations in GBM identified three main signalling pathways that are commonly dysregulated: activation of the receptor tyrosine kinase (RTK)/Ras/phosphoinositide 3kinase (PI3K) pathway (88\%), inhibition of p53 (87\%), and retinoblastoma protein $(\mathrm{Rb})$ signalling pathways (78\%) (34). Drugs targeting many of these commonly observed alterations have been investigated as potential targeted therapies for GBM.

\section{EphA3 Receptor Inhibitors}

The EphA3 receptor is overexpressed in $40-60 \%$ of GBM tumours and is commonly overexpressed in recurrent GBM (Table 1) (25). EphA3 is highly expressed on the tumourinitiating cell population in glioma, maintains tumour cells in a less differentiated and stem cell-like state, and its expression mediates the tumourigenic potential in GBM cells in vitro (26), suggesting that EphA3 may be a potential target for the treatment of GBM (Table 2).

A small molecule inhibitor of the EphA3 receptor, GLPG1790, has demonstrated superior tumour reduction in U251MG and U87MG subcutaneous xenograft models when compared to radiotherapy alone, however, GLPG1790 was not as effective as treatment with radiotherapy and concomitant temozolomide (54). Whilst GLPG1790 did not exhibit improved benefit over the current therapies, additional strategies for targeting EphA3 are being examined. An EphA3 monoclonal antibody (IIIA4) that binds the EphA3 globular ephrin-binding domain has been developed, and the humanised version (ifabotuzumab) is the subject of an investigator-sponsored Phase $0 / 1$ clinical trial currently underway in patients with recurrent GBM (55) to identify the optimal dose for tumour penetration. The IIIA4 antibody conjugated to the cytotoxic microtubule-targeting agent maytansine (IIIA4-USAN), induced apoptosis in four primary GBM cell lines in vitro, and significantly increased survival in an orthotopic model in vivo (55). Providing further evidence for the potential suitability of monoclonal antibodies targeting EphA3, a bispecific antibody against EphA2/A3 reduced clonogenicity in vitro and decreased tumour burden in vivo (56). Taken together, these studies indicate that EphA3 receptor inhibitors may be promising treatments for EphA3 receptor-amplified GBM, including recurrent disease, however, this remains to be tested in the clinic.

\section{EGFR Inhibitors}

Epidermal Growth Factor Receptor (EGFR) amplifications and mutations are detected in $40-60 \%$ of GBM cases (28, 96) (Table 1) and are generally indicative of poor prognosis (97). EGFR (also referred to as ERBB1 or HER1) is a member of the HER superfamily of RTKs, along with ERBB2, ERBB3, and ERBB4. Binding of a ligand to the ligandbinding site of these receptors induces receptor homo- or heterodimerisation, producing a conformational change that activates the intracellular tyrosine kinase domain. This results in autophosphorylation of the cytoplasmic tail and induces a variety of downstream signalling pathways. The overexpression or mutation of EGFR leads to downstream signalling that impairs apoptosis, enhances proliferation, and angiogenesis. The most common mutant form found in GBM is $\triangle$ EGFR (EGFRvIII, or de2-7EGFR), arising through an 801 base pair in-frame deletion from the extracellular domain (98). Due to the high incidence of EGFR amplifications, a variety of EGFR inhibitors have been examined both pre-clinically and clinically (Table 2).

\section{Small Molecule Inhibitors}

Small molecule tyrosine kinase inhibitors are the most widely studied EGFR inhibitors in GBM, and include erlotinib, gefitinib, and lapatinib. Erlotinib inhibits anchorage-independent growth of GBM cells in vitro in an EGFR expression-dependent manner and induces greater levels of apoptosis in more malignant GBM phenotypes (57). The tumour-initiating cell population, which is resistant to radiotherapy (99), is sensitive to erlotinib in a phosphatase and tensin homolog (PTEN) and Akt dependent manner (59), suggesting that erlotinib may eliminate this population in vivo. Further, treatment with erlotinib was shown to reduce tumour burden in two GBM patient-derived xenograft (PDX) models (60). However, further studies using additional GBM PDX models demonstrated that tumours overexpressing EGFR were only sensitive to erlotinib if they also expressed PTEN (61). As PTEN expression is downregulated in $\sim 34 \%$ of GBM patients (29), this indicates that erlotinib may not be a suitable treatment for the majority of GBM patients overexpressing EGFR. Indeed, erlotinib was not effective as a monotherapy in recurrent GBM patients and was only marginally beneficial following radiotherapy for non-progressive 
TABLE 1 | Commonly identified genetic alterations in GBM.

\begin{tabular}{|c|c|c|c|c|c|}
\hline Name & Function & Expression status & Prevalence & Prognosis & References \\
\hline EPHA3 & $\begin{array}{l}\text { Regulation of adhesive and repulsive } \\
\text { mechanisms including cell motility and } \\
\text { adhesion }\end{array}$ & Overexpressed & $40-60 \%$ & $\begin{array}{l}\text { Poor; over-expression } \\
\text { common in recurrent GBM }\end{array}$ & $(25-27)$ \\
\hline EGFR & $\begin{array}{l}\text { Regulation of processes involved in cell growth, } \\
\text { division and survival }\end{array}$ & Overexpressed & $40-60 \%$ & Poor & $(28-31)$ \\
\hline MGMT & Prevention of mismatch errors & Methylated & $40-60 \%$ & Favourable & $(32,33)$ \\
\hline CDKN2A & $\begin{array}{l}\text { Regulation of cell cycle and retinoblastoma } \\
\text { activation }\end{array}$ & Decreased & $49-52 \%$ & Poor & (34) \\
\hline PTEN & $\begin{array}{l}\text { Regulation of cell signalling. Involved in cell } \\
\text { proliferation and survival }\end{array}$ & Deleted and/or mutated & $34 \%$ & Poor & $(29,34-37)$ \\
\hline PIK3CA & $\begin{array}{l}\text { Regulation of processes involved in cell growth, } \\
\text { division and survival }\end{array}$ & Overexpressed and/or mutated & $15 \%$ & Poor; can predict recurrence & $(34,38,39)$ \\
\hline PDGFRA & $\begin{array}{l}\text { Regulation of processes involved in cell growth, } \\
\text { division and survival }\end{array}$ & Overexpressed & $13 \%$ & Poor & $(30,34,40,41)$ \\
\hline $\mathrm{IDH} 1$ & Production of NADPH & Mutated & $5-10 \%$ & Favourable & $(42,43)$ \\
\hline MDM2 & Regulation of p53 activity & Overexpressed & $8-9 \%$ & Unclear & $(44,45)$ \\
\hline MET & Regulation of proliferation, survival and motility & Overexpressed and/or mutated & $4-6 \%$ & Poor & $(34,46-49)$ \\
\hline SF/HGF & $\begin{array}{l}\text { Activating ligand for HGFR/c-MET. Tumour } \\
\text { growth and angiogenesis }\end{array}$ & Overexpressed & $1.6-4 \%$ & Poor & $(28,47,50)$ \\
\hline VEGF & Promotion of angiogenesis & Overexpressed and/or mutated & & Poor & $(51-53)$ \\
\hline
\end{tabular}

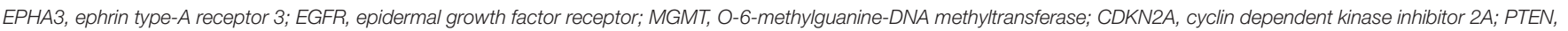

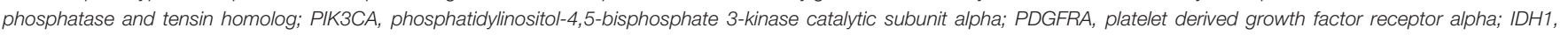

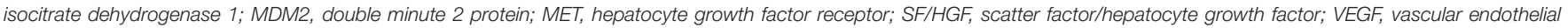
growth factor.

GBM patients (62). Despite a limited number of complete and partial responses in a Phase II study in first-relapse GBM, the 6-months PFS and median survival was similar to that previously reported for patients undergoing chemotherapy (64), suggesting that erlotinib may be useful in this setting. However, due to the non-randomised nature of this trial, these results must be interpreted cautiously. By contrast, improved survival (19.3 vs. 14.1 months) was observed when combined with temozolomide and radiotherapy (63), suggesting that erlotinib may be beneficial when combined with other treatments, rather than as monotherapy.

In contrast to erlotinib, gefitinib exhibits anti-tumour activity independent of the expression level of EGFR (100). Gefitinib inhibits GBM cell migration (65), reduces proliferation of human glioma tumour-initiating cells in vitro (59) and enhances survival in an intracranial GBM mouse xenograft model in vivo (58). Taken together, these pre-clinical studies indicate that gefitinib may be clinically beneficial. However, despite gefitinib reaching high concentrations in GBM tumour tissue (22-fold higher compared to plasma) and the significant dephosphorylation of EGFR achieved (66), limited clinical effects have been observed in Phase II trials. Several Phase I/II studies have demonstrated that whilst the addition of gefitinib to radiotherapy is well-tolerated, it has no survival benefit $(67,68)$.

\section{Monoclonal Antibodies}

Although tumour immunotherapy has shown some success for the treatment of melanoma and haematological cancers, the applicability to GBM presents more of a challenge. Monoclonal antibodies directed against wild-type EGFR and $\triangle \mathrm{EGFR}$ have been developed, with the best characterised in GBM being cetuximab. Pre-clinical studies have shown that treatment with cetuximab alone and in combination with radiotherapy increases survival in vivo (69) and can also completely eliminate tumours in EGFR-amplified PDX models (70). A phase II trial examining cetuximab treatment in patients with recurrent high-grade glioma showed that cetuximab was well-tolerated, but exhibited limited activity in this patient population (71).

\section{VEGF Inhibitors}

With the largely disappointing clinical results for EGFR inhibitors, additional targets are being investigated, including vascular endothelial growth factor (VEGF), which is highly expressed in glioma cells. High VEGF expression is directly associated with the poor prognosis and malignancy of gliomas (51-53, 101). VEGF is a dimeric polypeptide that binds to the VEGF receptors 1 (VEGFR-1) and VEGFR-2, and the coreceptors neuropilin 1 and 2. Following this interaction, VEGF mediates angiogenesis and cell proliferation. Under hypoxic conditions, hypoxia-inducible transcription factors translocate to the nucleus which activate VEGF leading to increased angiogenesis in an attempt to counteract hypoxia (102). GBM tumours are commonly hypoxic and have increased VEGF expression that contributes to the irregular vasculature in GBM, prompting the investigation of VEGF as a potential therapeutic target (Table 2).

\section{Small Molecule Inhibitors}

Several VEGF inhibitors have been examined for the treatment of GBM, including the small molecule inhibitors, tivozanib, and 
TABLE 2 | Targeted therapeutic outcomes in GBM.

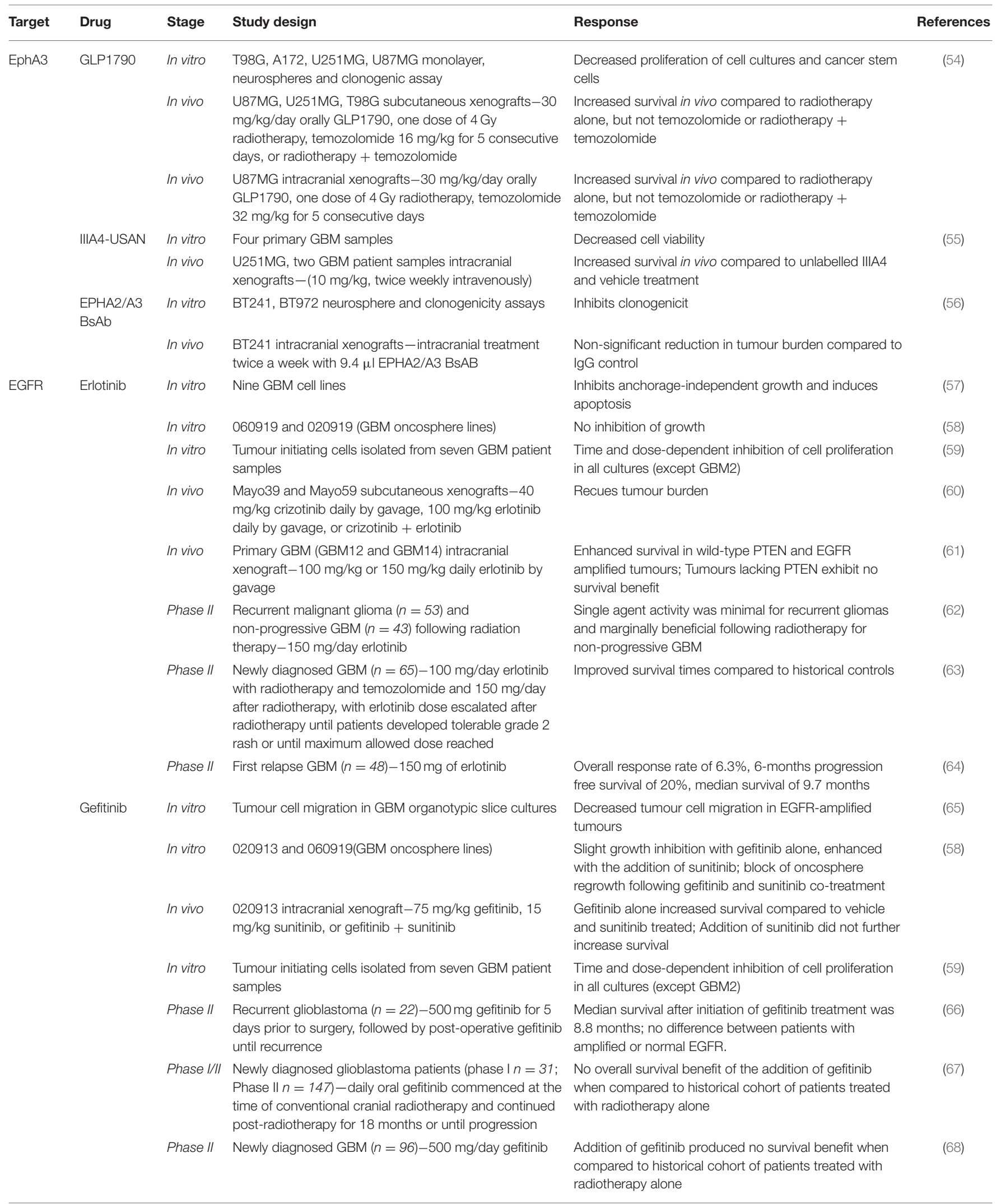


TABLE 2 | Continued

\begin{tabular}{|c|c|c|c|c|c|}
\hline Target & Drug & Stage & Study design & Response & References \\
\hline & Cetuximab & In vitro & Primary GBM (Ros57, Jon52, Mor56) & $\begin{array}{l}\text { Induced apoptosis as a monotherapy and when } \\
\text { combined with radiotherapy }\end{array}$ & (69) \\
\hline & & In vivo & $\begin{array}{l}\text { Ros57 subcutaneous xenograft }-0.5 \text { mg cetuximab } \\
\text { intraperitoneally twice per week for } 5 \text { weeks, or } \\
\text { cetuximab }+2 \text { or } 4 \text { Gy radiotherapy }\end{array}$ & $\begin{array}{l}\text { Arrest tumour growth (depended on size of tumour at } \\
\text { treatment commencement) }\end{array}$ & \\
\hline & & In vivo & $\begin{array}{l}\text { Ros57 or Jon52 intracranial xenografts }-0.5 \mathrm{mg} \\
\text { cetuximab intraperitoneally twice weekly for duration }\end{array}$ & Increased survival & \\
\hline & & In vitro & U373MG, U87MG, Ros57, Jon52, Mor56, Bai, Roc & Induced apoptosis in EGFR-amplified lines & $(70)$ \\
\hline & & In vivo & $\begin{array}{l}\text { Ros57, Jon52 subcutaneous xenograft-0.5 or } 1 \mathrm{mg} \\
\text { cetuximab intraperitoneally twice weekly }\end{array}$ & $\begin{array}{l}\text { Decreased tumour burden and increased survival, and } \\
\text { eliminated Ros } 57 \text { tumours }\end{array}$ & \\
\hline & & Phase II & $\begin{array}{l}\text { Recurrent high-grade glioma }(n=55)-400 \mathrm{mg} / \mathrm{m}^{2} \text { on } \\
\text { week } 1 \text { cetuximab intravenously, followed by weekly } \\
\text { dose of } 250 \mathrm{mg} / \mathrm{m}^{2}\end{array}$ & Well-tolerated but limited activity & $(71)$ \\
\hline \multirow[t]{7}{*}{ VEGF } & Bevacizumab & In vivo & $\begin{array}{l}\text { G55 intracranial xenograft-10-100 } \mu \mathrm{g} \text { intraperitoneally } \\
\text { twice weekly }\end{array}$ & Decreased tumour growth and vessel density & $(72)$ \\
\hline & & In vivo & $\begin{array}{l}\text { U87MG intracranial and intradermal xenograft-98.4 } \mu \mathrm{g} \\
\text { intraperitoneally every third day }\end{array}$ & Reduced vessel permeability and tumour volume & (73) \\
\hline & & In vivo & $\begin{array}{l}\text { U87MG subcutaneous xenograft-100 } \mu \mathrm{g} \\
\text { intraperitoneally every second day, six doses combined } \\
\text { with radiotherapy }\end{array}$ & $\begin{array}{l}\text { Decrease in tumour burden when used as a } \\
\text { monotherapy, and at least an additive increase when } \\
\text { combined with radiotherapy }\end{array}$ & $(74)$ \\
\hline & & In vivo & $\begin{array}{l}\text { U87MG intracerebral xenograft-1 mg intraperitoneal } \\
\text { every third day, three doses }\end{array}$ & Decreased tumour growth & $(75)$ \\
\hline & & $\begin{array}{l}\text { Meta- } \\
\text { analysis }\end{array}$ & Four clinical trials $(n=607)$ & $\begin{array}{l}\text { No difference in overall survival, modest increase in } \\
\text { progression-free survival when combined with } \\
\text { chemotherapy, compared with bevacizumab or } \\
\text { chemotherapy alone. Higher incidence of } \\
\text { treatment-related adverse events in bevacizumab treated } \\
\text { patients. }\end{array}$ & $(76)$ \\
\hline & Tivozanib & Phase II & $\begin{array}{l}\text { Recurrent glioblastoma }(n=10)-1.5 \mathrm{mg} \text { tivozanib daily, } \\
3 \text { weeks on/1 week off in 28-days cycles }\end{array}$ & $\begin{array}{l}\text { Despite functional changes in tumour vasculature, limited } \\
\text { anti-tumour activity was observed }\end{array}$ & $(77)$ \\
\hline & Pazopanib & Phase II & $\begin{array}{l}\text { Recurrent glioblastoma }(n=35)-800 \text { mg daily on } \\
\text { 4-weeks cycles }\end{array}$ & $\begin{array}{l}\text { Despite demonstrating biological activity (determined by } \\
\text { radiographic responses), single-agent pazopanib did not } \\
\text { prolong progression free survival }\end{array}$ & $(78)$ \\
\hline \multirow[t]{9}{*}{ PDGFR } & Imatinib & In vitro & U251MG and SF539 cell lines & Gleevec sensitised GBM cells to irradiation & (79) \\
\hline & & In vivo & $\begin{array}{l}\text { GL261 intracranial xenograft model-3 mg of Gleevec by } \\
\text { gavage on days } 5,7 \text {, and } 9,3 \text { Gy radiotherapy on Days } \\
5-9 \text {, or Gleevec + radiotherapy }\end{array}$ & $\begin{array}{l}\text { Gleevec monotherapy improved survival at a level similar } \\
\text { to radiotherapy, the combination of Gleevec and } \\
\text { radiotherapy significantly enhanced survival }\end{array}$ & $(80)$ \\
\hline & & In vivo & $\begin{array}{l}\text { U87MG intracranial xenograft-50 mg/kg } \\
\text { intraperitoneally }\end{array}$ & Increased survival & $(81)$ \\
\hline & & Phase II & $\begin{array}{l}\text { Recurrent GBM }(n=51)-800 \mathrm{mg} / \mathrm{d} \text { with dose } \\
\text { escalation to } 1,000 \mathrm{mg} / \mathrm{d}\end{array}$ & Well-tolerated but has limited anti-tumour activity & $(82)$ \\
\hline & & Phase III & $\begin{array}{l}\text { Progressive pre-treated GBM resistant to standard dose } \\
\text { temozolomide }(n=240)-600 \mathrm{mg} / \mathrm{d} \text { imatinib in } \\
\text { combination with } 1,000 \mathrm{mg} / \mathrm{d} \text { of hydroxyurea, or } 1,500 \\
\mathrm{mg} / \mathrm{d} \text { of hydroxyurea alone }\end{array}$ & $\begin{array}{l}\text { The addition of imatinib did not increase progression free } \\
\text { survival }\end{array}$ & (83) \\
\hline & Sunitinib & In vitro & $\begin{array}{l}\text { U87MG, GL15 cells implanted into organotypic brain } \\
\text { slices }\end{array}$ & Sunitinib induced apoptosis and decreased proliferation & $(84)$ \\
\hline & & In vivo & $\begin{array}{l}\text { U87MG intracerebral xenograft model- } 80 \mathrm{mg} / \mathrm{kg} \\
\text { sunitinib orally, } 5 \text { days on, } 2 \text { days off }\end{array}$ & $\begin{array}{l}\text { Improved median survival and reduced microvessel } \\
\text { density }\end{array}$ & \\
\hline & & In vivo & $\begin{array}{l}\text { PDGF-driven mouse model (PDGF-RES-Cre retrovirus } \\
\text { infection of adult glial progenitors in mice carrying } \\
\text { conditional deletions of PTEN and p53)- } 60 \mathrm{mg} / \mathrm{kg} \\
\text { sunitinib gavaged daily on a } 5 \text { day on, } 2 \text { days off cycle, } 2 \\
\text { or } 6 \text { Gy radiotherapy, or a combination of both }\end{array}$ & $\begin{array}{l}\text { Sunitinib or high-dose radiotherapy alone delayed } \\
\text { tumour growth and increased survival. The addition of } \\
\text { sunitinib to low-dose radiotherapy delayed tumour } \\
\text { growth, with no survival benefit. Sunitinib combined with } \\
\text { high dose radiotherapy induced a fatal toxicity. }\end{array}$ & (85) \\
\hline & & Phase /I & $\begin{array}{l}\text { Recurrent GBM }(n=6)-37.5 \mathrm{mg} / \text { day sunitinib for } 14 \\
\text { days }\end{array}$ & $\begin{array}{l}\text { Overall response rate was } 17 \% \text {, and } 6 \text {-months } \\
\text { progression free survival was not reach. Trial terminated } \\
\text { due to insufficient activity. }\end{array}$ & (86) \\
\hline
\end{tabular}


TABLE 2 | Continued

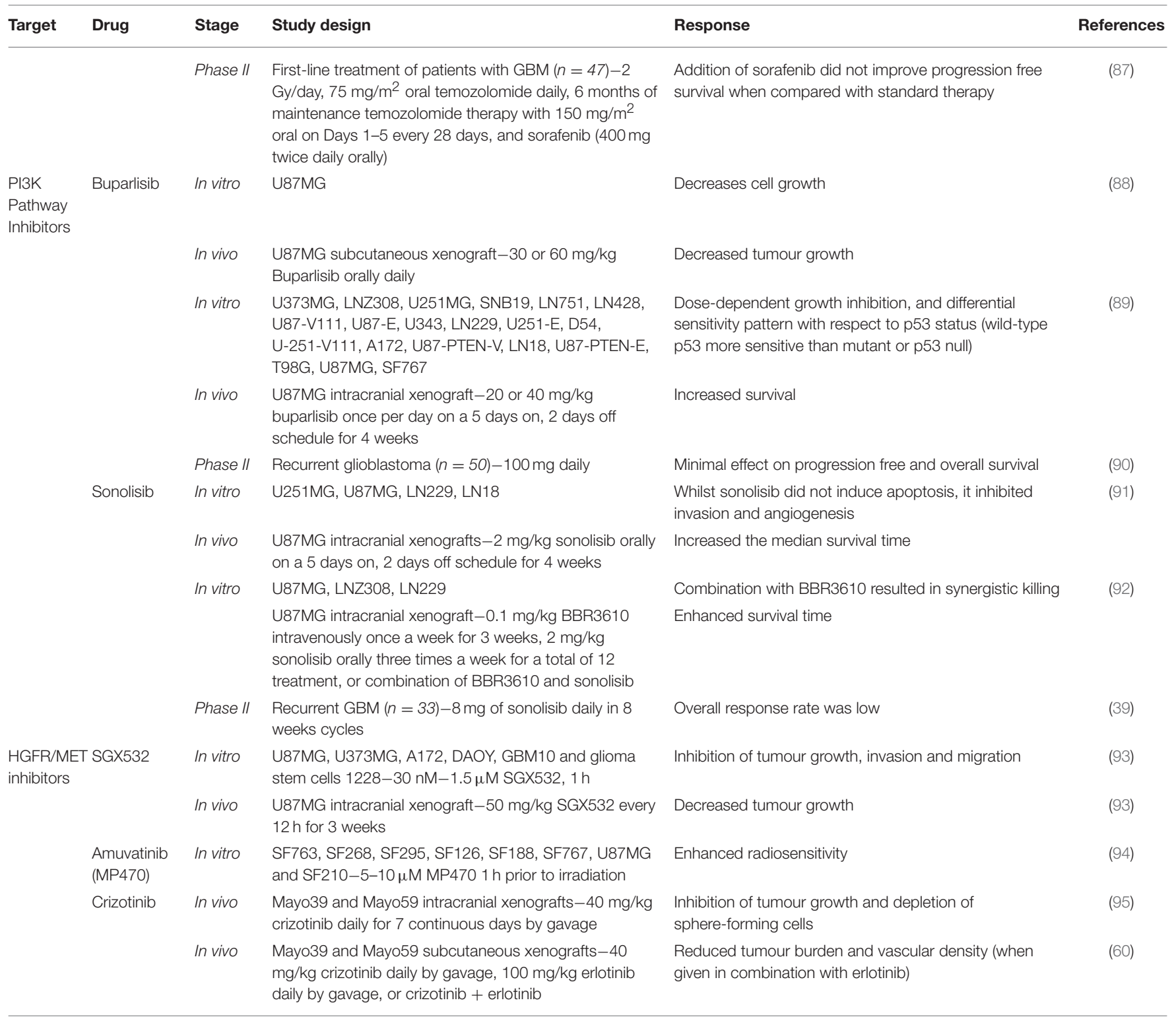

pazopanib. Phase II studies of tivozanib (77) and pazopanib (78) in recurrent glioblastoma showed that these inhibitors exhibited limited anti-tumour activity and did not prolong PFS in this patient population. These trials highlight the limitations of antiVEGF monotherapy.

\section{Monoclonal Antibodies}

Bevacizumab, a humanised monoclonal antibody against VEGF, blocks angiogenesis and thereby reduces tumour growth in a variety of GBM mouse models as a monotherapy and when combined with radiotherapy (72-75). These promising preclinical studies led to the clinical investigation and subsequent approval of bevacizumab for the treatment of recurrent GBM (103). However, a meta-analysis of four clinical trials including 607 patients demonstrated that the addition of bevacizumab to standard chemo-radiotherapy in the upfront setting only improves PFS, with no improvement in OS, but with an increase in the number of treatment-related adverse events (76). Of note, a decline in neurocognitive function is more frequently observed following bevacizumab treatment, as bevacizumab impairs hippocampal synaptic plasticity and decreases dendritic spine number and length (104). The modest treatment responses combined with the increased treatment-related adverse events raises concerns about the suitability of the use of bevacizumab as a treatment for GBM.

\section{Inhibition of Multiple RTKs}

Multiple RTKs are coactivated in GBM tumours (105), introducing redundancy and limiting the efficacy of therapies targeting single RTKs. EGFR and platelet derived growth factor 
receptor A (PDGFRA) protein co-expression occurs in 37\% of GBM (106). PDGFRA is the second most frequently amplified $(10-13 \%)$ receptor tyrosine kinase in $\operatorname{GBM}(28,107)$ (Table 1). A variety of multi-RTKs inhibitors have been examined both pre-clinically and clinically (Table 2 ).

Imatinib is a small molecule that inhibits PDGFRA and PDGFRB, as well as the RTKs c-Abl and c-Kit, and is a radiation-sensitising agent for glioma cells in vitro (79) and in orthotopic GBM models in vivo $(80,81)$. These promising preclinical studies led to the initiation of clinical trials. However, whilst imatinib was well-tolerated in recurrent GBM patients, it exhibited limited anti-tumour activity (82). Subsequent Phase III trials have examined imatinib in combination with hydroxyurea, rather than as a monotherapy (83). This trial showed that there was no PFS benefit to the addition of imatinib to hydroxyurea, or hydroxyurea alone. Further, a recent study has demonstrated that imatinib treatment can increase GBM cell migration and invasion in vitro (108), providing further potential insight as to why imatinib has failed in clinical trials for GBM.

Following the failure of imatinib in clinical trials, additional multi-RTK inhibitors have been studied. Sunitinib is an oral, small molecule that inhibits PDFR and VEGFR, and thereby reduces vascularisation and triggers apoptosis to produce tumour reduction. In pre-clinical models, sunitinib treatment induced apoptosis in vitro, and improved survival in an intracerebral GBM mouse model (84). Further, sunitinib treatment delayed tumour growth and increased survival in a PDGFF-driven mouse model, both as a monotherapy and in combination with low dose radiotherapy (85). By contrast, a Phase II trial and systematic review of the literature indicated that compared to conventional chemotherapy or bevacizumab, sunitinib has limited clinical activity in recurrent GBM as a monotherapy (86) or when combined with temozolomide or radiotherapy and temozolomide as a first-line treatment of patients with GBM (87).

\section{PI3K Pathway Inhibitors}

Genetic aberrations in GBM, including EGFR, PDGFRA, PTEN, TP53, and PIK3CA, drive the dysfunction of signalling pathways, including PI3K/Akt/mTOR, p53, and Rb1 (34). The PI3K/Akt signalling pathway is activated in most GBMs and plays a critical role in the regulation of signal transduction, and mediates a variety of cellular processes, including proliferation, survival, migration and angiogenesis in GBM. The PI3K/Akt pathway is typically initiated via the activation of RTKs or G proteincoupled receptors, were the conformational changes in the C-terminal kinase domain produced by autophosphorylation provides binding sites for the regulatory subunits of PI3K, which leads to elevated lipid kinase activity of PI3K, and activation of Akt. Despite the limited clinical efficacy of the previously described RTK inhibitors, as activation of each of these receptors leads to downstream activation of the PI3K/Akt pathway, it has therefore been suggested that PI3K pathway inhibitors may be beneficial in GBM. More than 50 PI3K inhibitors have been designed and are under investigation as treatments for a range of cancers. Several PI3K inhibitors have demonstrated pre-clinical efficacy in GBM (Table 2) and have entered into clinical trials for GBM treatment.
Buparlisib, a pan PI3K inhibitor, reduces GBM cell growth both in vitro and in vivo $(88,89)$. Buparlisib is the most frequently used PI3K inhibitor in clinical trials for GBM treatment, as it is well-tolerated and BBB permeable. However, single agent efficacy in Phase II trials in recurrent glioblastoma has been minimal (90). The lack of clinical efficacy was explained by incomplete blockade of the PI3K pathway in the tumour tissue. Whilst buparlisib showed minimal single-agent efficacy, the study of other PI3K inhibitors that achieve more-complete pathway inhibition may still be warranted.

Sonolisib is an irreversible wortmannin analogue that demonstrates a more persistent inhibitor effect on PI3K than wortmannin. Sonolisib inhibits invasion and angiogenesis in GBM cell lines in vitro and extends survival benefit in orthotopic xenograft models in vivo $(91,92)$. Despite these promising preclinical results, the response rate to sonolisib in a Phase II study in patients with recurrent GBM was low, and the study did not meet its primary endpoint (109).

\section{HGFR/MET Inhibitors}

Brain tumours secrete scatter factor (SF)/hepatocyte growth factor (HGF), the activating ligand for HGFR/MET (50), which has been associated with poor prognosis for GBM patients (Table 1) $(110,111)$. HGF is overexpressed in 1.6-4\% of GBM patients, and via activation of MET, enhances tumour growth and angiogenesis (28). The MET proto-oncogene encodes for MET, an RTK that is overexpressed in $4-6 \%$ of GBM patients. A mutated, constitutively active variant of MET, $\mathrm{MET}^{\Delta 7-8}$, has been identified in $6 \%$ of patients with high grade gliomas, including GBM, enhancing downstream signalling to promote tumour progression and angiogenesis (46).

SGX-523 is a small molecule inhibitor of HGFR/MET tyrosine kinase activity that inhibits tumour cell growth, migration and invasion in a panel of glioma cells in vitro and reduced tumour growth in a murine xenograft model of GBM using the U87MG GBM cell line (Table 2) (93). Additionally, amuvatinib (MP470) is a small molecule inhibitor that acts on multiple tyrosine kinases, including MET, has been shown to radiosensitise GBM cell lines both in vitro and in vivo (Table 2) (94).

Another small molecule inhibitor of MET kinase activity, crizotinib, inhibits the growth, sphere-forming capacity and expression of stem cell markers in a subcutaneous xenograft model of GBM using the U87MG cell line (95). However, in a subcutaneous xenograft model using Mayo39 and Mayo59 GBM cell lines, crizotinib was only effective at reducing tumour burden and vascular density when used in combination with the EGFR inhibitor erlotinib (60).

\section{CONCLUDING REMARKS}

GBM is an often-fatal disease and the standard treatment options available to patients are only minimally effective. There is a growing body of evidence suggesting that a personalised therapeutic approach for the stratification of GBM patients to novel treatment regimens is necessary if survival rates for GBM patients are to improve. Indeed, genetic profiling of GBM biopsies has revealed aberrant expression of several potential 
therapeutic targets, including a number of RTKs (EphA3, EGFR, VEGF, PDGFR, and MET), however, there has been varied and limited clinical success in the use of inhibitors of these targets as anti-cancer therapies. This highlights that a better understanding of the basic biology of GBM is required so that additional targets can be identified. Indeed, promising pre-clinical effects have been observed with EphA3 inhibitors, however, it remains to be seen whether this translates into the clinic. Whilst PI3K inhibitors have exhibited limited effects in clinical trials, they did not completely inhibit the PI3K pathway. Despite the promising outlook for personalised therapeutic approaches to treating GBM patients, the identification of therapeutics that can cross the $\mathrm{BBB}$, whilst maintaining therapeutic concentrations, remains a challenge and is often not reported. Further, although targeted therapies show limited efficacy as single agents, the combination of several targeted therapies may be of benefit to

\section{REFERENCES}

1. Jemal A, Siegel R, Xu J, Ward E. Cancer statistics, 2010. CA Cancer J Clin. (2010) 60:277-300. doi: 10.3322/caac.20073

2. Iacob G, Dinca EB. Current data and strategy in glioblastoma multiforme. $J$ Med Life. (2009) 2:386-393.

3. Dobes M, Khurana VG, Shadbolt B, Jain S, Smith SF, Smee R, et al. Increasing incidence of glioblastoma multiforme and meningioma, and decreasing incidence of Schwannoma (2000-2008): findings of a multicenter Australian study. Surg Neurol Int. (2011) 2:176. doi: 10.4103/2152-7806. 90696

4. Ostrom QT, Gittleman H, Fulop J, Liu M, Blanda R, Kromer C, et al. CBTRUS statistical report: primary brain and central nervous system tumors diagnosed in the United States in 2008-2012. Neuro Oncol. (2015) 17(Suppl. 4):iv1-62. doi: 10.1093/neuonc/nov189

5. Zhu P, Du XL, Lu G, Zhu JJ. Survival benefit of glioblastoma patients after FDA approval of temozolomide concomitant with radiation and bevacizumab: a population-based study. Oncotarget. (2017) 8:44015-31. doi: 10.18632/oncotarget.17054

6. Louis DN, Perry A, Reifenberger G, von Deimling A, Figarella-Branger D, Cavenee WK, et al. The 2016 World Health Organization classification of tumors of the central nervous system: a summary. Acta Neuropathol. (2016) 131:803-20. doi: 10.1007/s00401-016-1545-1

7. Kleihues $\mathrm{P}$, Ohgaki H. Primary and secondary glioblastomas: from concept to clinical diagnosis. Neuro Oncol. (1999) 1:44-51. doi: 10.1093/neuonc/1.1.44

8. Ohgaki H, Kleihues P. The definition of primary and secondary glioblastoma. Clin Cancer Res. (2013) 19:764-72. doi: 10.1158/1078-0432.CCR-12-3002

9. Kakee A, Terasaki T, Sugiyama Y. Brain efflux index as a novel method of analyzing efflux transport at the blood-brain barrier. J Pharmacol Exp Ther. (1996) 277:1550-9.

10. Gan HK, van den Bent M, Lassman AB, Reardon DA, Scott AM. Antibodydrug conjugates in glioblastoma therapy: the right drugs to the right cells. Nat Rev Clin Oncol. (2017) 14:695-707. doi: 10.1038/nrclinonc.2017.95

11. Xu YY, Gao P, Sun Y, Duan YR. Development of targeted therapies in treatment of glioblastoma. Cancer Biol Med. (2015) 12:223-37. doi: $10.7497 /$ j.issn.2095-3941.2015.0020

12. Davis ME. Glioblastoma: overview of disease and treatment. Clin J Oncol Nurs. (2016) 20:S2-8. doi: 10.1188/16.CJON.S1.2-8

13. Stupp R, Mason WP, van den Bent MJ, Weller M, Fisher B, Taphoorn MJ, et al. Radiotherapy plus concomitant and adjuvant temozolomide for glioblastoma. N Engl J Med. (2005) 352:987-96. doi: 10.1056/NEJMoa043330

14. Allahdini F, Amirjamshidi A, Reza-Zarei M, Abdollahi M. Evaluating the prognostic factors effective on the outcome of patients with glioblastoma multiformis: does maximal resection of the tumor lengthen the median survival? World Neurosurg. (2010) 73:128-34; discussion: e16. doi: 10.1016/j.wneu.2009.06.001
GBM patients. Thus, additional research is urgently required to identify therapeutic targets in GBM and to design novel therapeutic strategies for the treatment of GBM.

\section{AUTHOR CONTRIBUTIONS}

$\mathrm{OT}$ and JB drafted the manuscript and reviewed the literature. OT, JB, and KS contributed to the preparation and editing of the manuscript. KS formulated the idea.

\section{FUNDING}

This work was funded by research funds received from the Mark Hughes Foundation through the Hunter Medical Research Institute, and the University of Newcastle.
15. Vogelbaum MA. Does extent of resection of a glioblastoma matter? Clin Neurosurg. (2012) 59:79-81. doi: 10.1227/NEU.0b013e31826b2e75

16. Perkins A, Liu G. Primary brain tumors in adults: diagnosis and treatment. Am Fam Physician. (2016) 93:211-7.

17. Sathornsumetee S, Rich JN. New approaches to primary brain tumor treatment. Anticancer Drugs. (2006) 17:1003-16. doi: 10.1097/01.cad.0000231473.00030.1f

18. Gallego O. Nonsurgical treatment of recurrent glioblastoma. Curr Oncol. (2015) 22:e273-81. doi: 10.3747/co.22.2436

19. Happold C, Roth P, Wick W, Schmidt N, Florea AM, Silginer M, et al. Distinct molecular mechanisms of acquired resistance to temozolomide in glioblastoma cells. J Neurochem. (2012) 122:444-55. doi: 10.1111/j.1471-4159.2012.07781.x

20. Felsberg J, Rapp M, Loeser S, Fimmers R, Stummer W, Goeppert M, et al. Prognostic significance of molecular markers and extent of resection in primary glioblastoma patients. Clin Cancer Res. (2009) 15:6683-93. doi: 10.1158/1078-0432.CCR-08-2801

21. Osuka S, Van Meir EG. Overcoming therapeutic resistance in glioblastoma: the way forward. J Clin Invest. (2017) 127:415-26. doi: 10.1172/JCI 89587

22. Weller M, van den Bent M, Tonn JC, Stupp R, Preusser M, CohenJonathan-Moyal E, et al. European Association for Neuro-Oncology (EANO) guideline on the diagnosis and treatment of adult astrocytic and oligodendroglial gliomas. Lancet Oncol. (2017) 18:e315-29. doi: 10.1016/S1470-2045(17)30194-8

23. Branter J, Basu S, Smith S. Tumour treating fields in a combinational therapeutic approach. Oncotarget. (2018) 9:36631-44. doi: 10.18632/oncotarget.26344

24. Yi Y, Hsieh IY, Huang X, Li J, Zhao W. Glioblastoma stem-like cells: characteristics, microenvironment, and therapy. Front Pharmacol. (2016) 7:477. doi: 10.3389/fphar.2016.00477

25. Ferluga S, Tomé CM, Herpai DM, D’Agostino R, Debinski W. Simultaneous targeting of Eph receptors in glioblastoma. Oncotarget. (2016) 7:59860-76. doi: 10.18632/oncotarget.10978

26. Day BW, Stringer BW, Al-Ejeh F, Ting MJ, Wilson J, Ensbey KS, et al. EphA3 maintains tumorigenicity and is a therapeutic target in glioblastoma multiforme. Cancer Cell. (2013) 23:238-48. doi: 10.1016/j.ccr.2013.01.007

27. Wykosky J, Gibo DM, Debinski W. A novel, potent, and specific ephrinA1based cytotoxin against EphA2 receptor expressing tumor cells. Mol Cancer Ther. (2007) 6:3208-18. doi: 10.1158/1535-7163.MCT-07-0200

28. Brennan CW, Verhaak RG, McKenna A, Campos B, Noushmehr H, Salama $\mathrm{SR}$, et al. The somatic genomic landscape of glioblastoma. Cell. (2013) 155:462-77. doi: 10.1016/j.cell.2013.09.034

29. An Z, Aksoy O, Zheng T, Fan QW, Weiss WA. Epidermal growth factor receptor and EGFRvIII in glioblastoma: signaling pathways and targeted therapies. Oncogene. (2018) 37:1561-75. doi: 10.1038/s41388-017-0045-7 
30. Furnari FB, Cloughesy TF, Cavenee WK, Mischel PS. Heterogeneity of epidermal growth factor receptor signalling networks in glioblastoma. Nat Rev Cancer. (2015) 15:302-10. doi: 10.1038/nrc3918

31. Hu X, Miao W, Zou Y, Zhang W, Zhang Y, Liu H. Expression of p53, epidermal growth factor receptor, Ki-67 and O6-methylguanineDNA methyltransferase in human gliomas. Oncol Lett. (2013) 6:130-4. doi: 10.3892/ol.2013.1317

32. Hegi ME, Diserens AC, Gorlia T, Hamou MF, de Tribolet N, Weller M, et al. MGMT gene silencing and benefit from temozolomide in glioblastoma. $N$ Engl J Med. (2005) 352:997-1003. doi: 10.1056/NEJMoa043331

33. Shen D, Liu T, Lin Q, Lu X, Wang Q, Lin F, et al. MGMT promoter methylation correlates with an overall survival benefit in Chinese highgrade glioblastoma patients treated with radiotherapy and alkylating agentbased chemotherapy: a single-institution study. PLOS ONE. (2014) 9:e107558. doi: 10.1371/journal.pone.0107558

34. The Cancer Genome Atlas Research Network (TCGA). Comprehensive genomic characterization defines human glioblastoma genes and core pathways. Nature. (2008) 455:1061-8. doi: 10.1038/nature07385

35. Benitez JA, Ma J, D’Antonio M, Boyer A, Camargo MF, Zanca C, et al. PTEN regulates glioblastoma oncogenesis through chromatin-associated complexes of DAXX and histone H3.3. Nat Commun. (2017) 8:15223. doi: 10.1038/ncomms15223

36. Zheng H, Ying H, Yan H, Kimmelman AC, Hiller DJ, Chen AJ, et al. p53 and Pten control neural and glioma stem/progenitor cell renewal and differentiation. Nature. (2008) 455:1129-33. doi: 10.1038/nature07443

37. Walker C, Baborie A, Crooks D, Wilkins S, Jenkinson MD. Biology, genetics and imaging of glial cell tumours. Br J Radiol. (2011) 84:S90-106. doi: 10.1259/bjr/23430927

38. Gallia GL, Rand V, Siu IM, Eberhart CG, James CD, Marie SK, et al. PIK3CA gene mutations in pediatric and adult glioblastoma multiforme. Mol Cancer Res. (2006) 4:709-14. doi: 10.1158/1541-7786.MCR-06-0172

39. Zhao HF, Wang J, Shao W, Wu CP, Chen ZP, To ST, et al. Recent advances in the use of PI3K inhibitors for glioblastoma multiforme: current preclinical and clinical development. Mol Cancer. (2017) 16:100. doi: 10.1186/s12943-017-0670-3

40. Koschmann C, Zamler D, MacKay A, Robinson D, Wu YM, Doherty R, et al. Characterizing and targeting PDGFRA alterations in pediatric high-grade glioma. Oncotarget. (2016) 7:65696-06. doi: 10.18632/oncotarget.11602

41. Cantanhede IG, de Oliveira JRM. PDGF family expression in glioblastoma multiforme: data compilation from Ivy glioblastoma atlas project database. Sci Rep. (2017) 7:15271. doi: 10.1038/s41598-017-15045-w

42. SongTao Q, Lei Y, Si G, YanQing D, HuiXia H, XueLin Z, et al. IDH mutations predict longer survival and response to temozolomide in secondary glioblastoma. Cancer Sci. (2012) 103:269-73. doi: $10.1111 /$ j.1349-7006.2011.02134.x

43. Cohen AL, Holmen SL, Colman H. IDH1 and IDH2 mutations in gliomas. Curr Neurol Neurosci Rep. (2013) 13:345. doi: 10.1007/s11910-013-0345-4

44. Verreault M, Schmitt C, Goldwirt L, Pelton K, Haidar S, Levasseur C, et al. Preclinical efficacy of the MDM2 inhibitor RG7112 in MDM2-amplified and TP53 wild-type glioblastomas. Clin Cancer Res. (2016) 22:1185-96. doi: 10.1158/1078-0432.CCR-15-1015

45. Reifenberger G, Liu L, Ichimura K, Schmidt EE, Collins VP. Amplification and overexpression of the MDM2 gene in a subset of human malignant gliomas without p53 mutations. Cancer Res. (1993) 53:2736-9.

46. Navis AC, van Lith SA, van Duijnhoven SM, de Pooter M, Yetkin-Arik B, Wesseling $\mathrm{P}$, et al. Identification of a novel MET mutation in high-grade glioma resulting in an auto-active intracellular protein. Acta Neuropathol. (2015) 130:131-44. doi: 10.1007/s00401-015-1420-5

47. Cruickshanks N, Zhang Y, Yuan F, Pahuski M, Gibert M, Abounader R. Role and therapeutic targeting of the HGF/MET pathway in glioblastoma. Cancers. (2017) 9:E87. doi: 10.3390/cancers9070087

48. Miyamoto M, Ojima $H$, Iwasaki $M$, Shimizu $H$, Kokubu A, Hiraoka N, et al. Prognostic significance of overexpression of c-Met oncoprotein in cholangiocarcinoma. Br J Cancer. (2011) 105:131-8. doi: 10.1038/bjc.2011.199

49. Kwak Y, Kim SI, Park CK, Paek SH, Lee ST, Park SH. C-MET overexpression and amplification in gliomas. Int $J$ Clin Exp Pathol. (2015) 8:14932-8.
50. Abounader R, Laterra J. Scatter factor/hepatocyte growth factor in brain tumor growth and angiogenesis. Neuro Oncol. (2005) 7:436-51. doi: $10.1215 /$ S1152851705000050

51. Das S, Marsden PA. Angiogenesis in glioblastoma. N Engl J Med. (2013) 369:1561-3. doi: 10.1056/NEJMcibr1309402

52. Plate KH, Breier G, Millauer B, Ullrich A, Risau W. Up-regulation of vascular endothelial growth factor and its cognate receptors in a rat glioma model of tumor angiogenesis. Cancer Res. (1993) 53:5822-7.

53. Ma C, Li Y, Zhang X, Zhao G, Xu H. Levels of vascular endothelial growth factor and matrix metalloproteinase- 9 proteins in patients with glioma. J Int Med Res. (2014) 42:198-204. doi: 10.1177/0300060513 481924

54. Gravina GL, Mancini A, Colapietro A, Delle Monache S, Sferra R, Vitale F, et al. The small molecule ephrin receptor inhibitor, GLPG1790, reduces renewal capabilities of cancer stem cells, showing anti-tumour efficacy on preclinical glioblastoma models. Cancers. (2019) 11:E359. doi: 10.3390/cancers11030359

55. Offenhäuser C, Al-Ejeh F, Puttick S, Ensbey KS, Bruce ZC, Jamieson PR, et al. EphA3 pay-loaded antibody therapeutics for the treatment of glioblastoma. Cancers. (2018) 10:E519. doi: 10.3390/cancers10120519

56. Qazi MA, Vora P, Venugopal C, Adams J, Singh M, Hu A, et al. Cotargeting ephrin receptor tyrosine kinases A2 and A3 in cancer stem cells reduces growth of recurrent glioblastoma. Cancer Res. (2018) 78:5023-37. doi: 10.1158/0008-5472.CAN-18-0267

57. Halatsch ME, Gehrke EE, Vougioukas VI, Bötefür IC, A-Borhani F, Efferth $\mathrm{T}$, et al. Inverse correlation of epidermal growth factor receptor messenger RNA induction and suppression of anchorage-independent growth by OSI-774, an epidermal growth factor receptor tyrosine kinase inhibitor, in glioblastoma multiforme cell lines. J Neurosurg. (2004) 100:523-33. doi: $10.3171 /$ jns.2004.100.3.0523

58. Joshi AD, Loilome W, Siu IM, Tyler B, Gallia GL, Riggins GJ. Evaluation of tyrosine kinase inhibitor combinations for glioblastoma therapy. PLoS ONE. (2012) 7:e44372. doi: 10.1371/journal.pone.0044372

59. Griffero F, Daga A, Marubbi D, Capra MC, Melotti A, Pattarozzi A, et al. Different response of human glioma tumor-initiating cells to epidermal growth factor receptor kinase inhibitors. J Biol Chem. (2009) 284:7138-48. doi: 10.1074/jbc.M807111200

60. Goodwin CR, Rath P, Oyinlade O, Lopez H, Mughal S, Xia S, et al. Crizotinib and erlotinib inhibits growth of c-Met+/EGFRvIII+ primary human glioblastoma xenografts. Clin Neurol Neurosurg. (2018) 171:26-33. doi: 10.1016/j.clineuro.2018.02.041

61. Sarkaria JN, Yang L, Grogan PT, Kitange GJ, Carlson BL, Schroeder $\mathrm{MA}$, et al. Identification of molecular characteristics correlated with glioblastoma sensitivity to EGFR kinase inhibition through use of an intracranial xenograft test panel. Mol Cancer Ther. (2007) 6:1167-74. doi: 10.1158/1535-7163.MCT-06-0691

62. Raizer JJ, Abrey LE, Lassman AB, Chang SM, Lamborn KR, Kuhn JG, et al. A phase II trial of erlotinib in patients with recurrent malignant gliomas and nonprogressive glioblastoma multiforme postradiation therapy. Neuro Oncol. (2010) 12:95-103. doi: 10.1093/neuonc/nop015

63. Prados MD, Chang SM, Butowski N, DeBoer R, Parvataneni R, Carliner H, et al. Phase II study of erlotinib plus temozolomide during and after radiation therapy in patients with newly diagnosed glioblastoma multiforme or gliosarcoma. J Clin Oncol. (2009) 27:579-84. doi: 10.1200/JCO.2008.18.9639

64. Yung WK, Vredenburgh JJ, Cloughesy TF, Nghiemphu P, Klencke $B$, Gilbert MR, et al. Safety and efficacy of erlotinib in first-relapse glioblastoma: a phase II open-label study. Neuro Oncol. (2010) 12:1061-70. doi: 10.1093/neuonc/noq072

65. Parker JJ, Dionne KR, Massarwa R, Klaassen M, Foreman NK, Niswander L, et al. Gefitinib selectively inhibits tumor cell migration in EGFRamplified human glioblastoma. Neuro Oncol. (2013) 15:1048-57. doi: 10.1093/neuonc/not053

66. Hegi ME, Diserens AC, Bady P, Kamoshima Y, Kouwenhoven MC, Delorenzi $\mathrm{M}$, et al. Pathway analysis of glioblastoma tissue after preoperative treatment with the EGFR tyrosine kinase inhibitor gefitinib-a phase II trial. Mol Cancer Ther. (2011) 10:1102-12. doi: 10.1158/1535-7163.MCT-11-0048

67. Chakravarti A, Wang M, Robins HI, Lautenschlaeger T, Curran WJ, Brachman DG, et al. RTOG 0211: a phase $1 / 2$ study of radiation therapy with 
concurrent gefitinib for newly diagnosed glioblastoma patients. Int J Radiat Oncol Biol Phys. (2013) 85:1206-11. doi: 10.1016/j.ijrobp.2012.10.008

68. Uhm JH, Ballman KV, Wu W, Giannini C, Krauss JC, Buckner JC, et al. Phase II evaluation of gefitinib in patients with newly diagnosed Grade 4 astrocytoma: Mayo/North Central Cancer Treatment Group study N0074. Int J Radiat Oncol Biol Phys. (2011) 80:347-53. doi: 10.1016/j.ijrobp.2010.01.070

69. Eller JL, Longo SL, Kyle MM, Bassano D, Hicklin DJ, Canute GW. Anti-epidermal growth factor receptor monoclonal antibody cetuximab augments radiation effects in glioblastoma multiforme in vitro and in vivo. Neurosurgery. (2005) 56:155-62. doi: 10.1227/01.NEU.0000145865.25689.55

70. Eller JL, Longo SL, Hicklin DJ, Canute GW. Activity of anti-epidermal growth factor receptor monoclonal antibody C225 against glioblastoma multiforme. Neurosurgery. (2002) 51:1005-13; discussion: 1013-4. doi: 10.1227/00006123-200210000-00028

71. Neyns B, Sadones J, Joosens E, Bouttens F, Verbeke L, Baurain JF, et al. Stratified phase II trial of cetuximab in patients with recurrent high-grade glioma. Ann Oncol. (2009) 20:1596-603. doi: 10.1093/annonc/mdp032

72. Kim KJ, Li B, Winer J, Armanini M, Gillett N, Phillips HS, et al. Inhibition of vascular endothelial growth factor-induced angiogenesis suppresses tumour growth in vivo. Nature. (1993) 362:841-4. doi: 10.1038/362841a0

73. Yuan F, Chen Y, Dellian M, Safabakhsh N, Ferrara N, Jain RK. Timedependent vascular regression and permeability changes in established human tumor xenografts induced by an anti-vascular endothelial growth factor/vascular permeability factor antibody. Proc Natl Acad Sci USA. (1996) 93:14765-70. doi: 10.1073/pnas.93.25.14765

74. Lee CG, Heijn M, di Tomaso E, Griffon-Etienne G, Ancukiewicz M, Koike $\mathrm{C}$, et al. Anti-vascular endothelial growth factor treatment augments tumor radiation response under normoxic or hypoxic conditions. Cancer Res. (2000) 60:5565-70.

75. Gossmann A, Helbich TH, Kuriyama N, Ostrowitzki S, Roberts TP, Shames $\mathrm{DM}$, et al. Dynamic contrast-enhanced magnetic resonance imaging as a surrogate marker of tumor response to anti-angiogenic therapy in a xenograft model of glioblastoma multiforme. J Magn Reson Imaging. (2002) 15:233-240. doi: 10.1002/jmri.10072

76. Yang SB, Gao KD, Jiang T, Cheng SJ, Li WB. Bevacizumab combined with chemotherapy for glioblastoma: a meta-analysis of randomized controlled trials. Oncotarget. (2017) 8:57337-44. doi: 10.18632/oncotarget.16924

77. Kalpathy-Cramer J, Chandra V, Da X, Ou Y, Emblem KE, Muzikansky A, et al. Phase II study of tivozanib, an oral VEGFR inhibitor, in patients with recurrent glioblastoma. J Neurooncol. (2017) 131:603-10. doi: 10.1007/s11060-016-2332-5

78. Iwamoto FM, Lamborn KR, Robins HI, Mehta MP, Chang SM, Butowski NA, et al. Phase II trial of pazopanib (GW786034), an oral multi-targeted angiogenesis inhibitor, for adults with recurrent glioblastoma (North American Brain Tumor Consortium Study 06-02). Neuro Oncol. (2010) 12:855-61. doi: 10.1093/neuonc/noq025

79. Russell JS, Brady K, Burgan WE, Cerra MA, Oswald KA, Camphausen K, et al. Gleevec-mediated inhibition of Rad51 expression and enhancement of tumor cell radiosensitivity. Cancer Res. (2003) 63:7377-83.

80. Geng L, Shinohara ET, Kim D, Tan J, Osusky K, Shyr Y, et al. STI571 (Gleevec) improves tumor growth delay and survival in irradiated mouse models of glioblastoma. Int J Radiat Oncol Biol Phys. (2006) 64:263-71. doi: 10.1016/j.ijrobp.2005.08.025

81. Kilic T, Alberta JA, Zdunek PR, Acar M, Iannarelli P, O’Reilly T, et al. Intracranial inhibition of platelet-derived growth factor-mediated glioblastoma cell growth by an orally active kinase inhibitor of the 2phenylaminopyrimidine class. Cancer Res. (2000) 60:5143-50.

82. Raymond E, Brandes AA, Dittrich C, Fumoleau P, Coudert B, Clement PMJ, et al. Phase II study of imatinib in patients with recurrent gliomas of various histologies: a European Organisation for Research and Treatment of Cancer Brain Tumor Group Study. J Clin Oncol. (2008) 26:4659-65. doi: 10.1200/JCO.2008.16.9235

83. Dresemann G, Weller M, Rosenthal MA, Wedding U, Wagner W, Engel $\mathrm{E}$, et al. Imatinib in combination with hydroxyurea versus hydroxyurea alone as oral therapy in patients with progressive pretreated glioblastoma resistant to standard dose temozolomide. J Neurooncol. (2010) 96:393-402. doi: 10.1007/s11060-009-9976-3
84. de Boüard S, Herlin P, Christensen JG, Lemoisson E, Gauduchon P, Raymond E, et al. Antiangiogenic and anti-invasive effects of sunitinib on experimental human glioblastoma. Neuro Oncol. (2007) 9:412-23. doi: 10.1215/15228517-2007-024

85. D’Amico R, Lei L, Kennedy BC, Sisti J, Ebiana V, Crisman C, et al. The addition of Sunitinib to radiation delays tumor growth in a murine model of glioblastoma. Neurol Res. (2012) 34:252-61. doi: 10.1179/1743132812Y.0000000005

86. Grisanti S, Ferrari VD, Buglione M, Agazzi GM, Liserre R, Poliani L, et al. Second line treatment of recurrent glioblastoma with sunitinib: results of a phase II study and systematic review of literature. J Neurosurg Sci. (2019) 63:458-67. doi: 10.23736/S0390-5616.16.03874-1

87. Hainsworth JD, Ervin T, Friedman E, Priego V, Murphy PB, Clark BL, et al. Concurrent radiotherapy and temozolomide followed by temozolomide and sorafenib in the first-line treatment of patients with glioblastoma multiforme. Cancer. (2010) 116:3663-9. doi: 10.1002/cncr.25275

88. Burger MT, Pecchi S, Wagman A, Ni ZJ, Knapp M, Hendrickson T, et al. Identification of NVP-BKM120 as a potent, selective, orally bioavailable class I PI3 kinase inhibitor for treating cancer. ACS Med Chem Lett. (2011) 2:774-9. doi: 10.1021/ml200156t

89. Koul D, Fu J, Shen R, LaFortune TA, Wang S, Tiao N, et al. Antitumor activity of NVP-BKM120-a selective pan class I PI3 kinase inhibitor showed differential forms of cell death based on p53 status of glioma cells. Clin Cancer Res. (2012) 18:184-95. doi: 10.1158/1078-0432.CCR-111558

90. Wen PY, Touat M, Alexander BM, Mellinghoff IK, Ramkissoon S, McCluskey CS, et al. Buparlisib in patients with recurrent glioblastoma harboring phosphatidylinositol 3-kinase pathway activation: an open-label, multicenter, multi-arm, phase II trial. J Clin Oncol. (2019) 37:741-50. doi: 10.1200/JCO.18.01207

91. Koul D, Shen R, Kim YW, Kondo Y, Lu Y, Bankson J, et al. Cellular and in vivo activity of a novel PI3K inhibitor, PX-866, against human glioblastoma. Neuro Oncol. (2010) 12:559-69. doi: 10.1093/neuonc/ nop058

92. Gwak HS, Shingu T, Chumbalkar V, Hwang YH, DeJournett R, Latha K, et al. Combined action of the dinuclear platinum compound BBR3610 with the PI3-K inhibitor PX-866 in glioblastoma. Int J Cancer. (2011) 128:787-96. doi: 10.1002/ijc.25394

93. Guessous F, Zhang Y, diPierro C, Marcinkiewicz L, Sarkaria J, Schiff D, et al. An orally bioavailable c-Met kinase inhibitor potently inhibits brain tumor malignancy and growth. Anticancer Agents Med Chem. (2010) 10:28-35. doi: 10.2174/1871520611009010028

94. Welsh JW, Mahadevan D, Ellsworth R, Cooke L, Bearss D, Stea B. The c-Met receptor tyrosine kinase inhibitor MP470 radiosensitizes glioblastoma cells. Radiat Oncol. (2009) 4:69. doi: 10.1186/1748-717X-4-69

95. Rath P, Lal B, Ajala O, Li Y, Xia S, Kim J, et al. In vivo c-met pathway inhibition depletes human glioma xenografts of tumor-propagating stemlike cells. Transl Oncol. (2013) 6:104-11. doi: 10.1593/tlo.13127

96. Li J, Di C, Mattox AK, Wu L, Adamson DC. The future role of personalized medicine in the treatment of glioblastoma multiforme. Pharmgenomics Pers Med. (2010) 3:111-27. doi: 10.2147/PGPM.S6852

97. Li J, Liang R, Song C, Xiang Y, Liu Y. Prognostic significance of epidermal growth factor receptor expression in glioma patients. Onco Targets Ther. (2018) 11:731-42. doi: 10.2147/OTT.S155160

98. Gan HK, Kaye AH, Luwor RB. The EGFRvIII variant in glioblastoma multiforme. J Clin Neurosci. (2009) 16:748-54. doi: 10.1016/j.jocn.2008.12.005

99. Bao S, Wu Q, McLendon RE, Hao Y, Shi Q, Hjelmeland AB, et al. Glioma stem cells promote radioresistance by preferential activation of the DNA damage response. Nature. (2006) 444:756-60. doi: 10.1038/nature05236

100. Mellinghoff IK, Wang MY, Vivanco I, Haas-Kogan DA, Zhu S, Dia EQ, et al. Molecular determinants of the response of glioblastomas to EGFR kinase inhibitors. N Engl J Med. (2005) 353:2012-24. doi: 10.1056/NEJMoa051918

101. Li Q, Qiao G, Ma J, Li Y. Downregulation of VEGF expression attenuates malignant biological behavior of C6 glioma stem cells. Int J Oncol. (2014) 44:1581-8. doi: 10.3892/ijo.2014.2331

102. Shibuya M. Structure and function of VEGF/VEGF-receptor system involved in angiogenesis. Cell Struct Funct. (2001) 26:25-35. doi: 10.1247/csf.26.25 
103. Cohen MH, Shen YL, Keegan P, Pazdur R. FDA drug approval summary: bevacizumab (Avastin) as treatment of recurrent glioblastoma multiforme. Oncologist. (2009) 14:1131-8. doi: 10.1634/theoncologist.2009-0121

104. Latzer P, Shchyglo O, Hartl T, Matschke V, Schlegel U, Manahan-Vaughan $\mathrm{D}$, et al. Blocking VEGF by bevacizumab compromises electrophysiological and morphological properties of hippocampal neurons. Front Cell Neurosci. (2019) 13:113. doi: 10.3389/fncel.2019.00113

105. Stommel JM, Kimmelman AC, Ying H, Nabioullin R, Ponugoti AH, Wiedemeyer R, et al. Coactivation of receptor tyrosine kinases affects the response of tumor cells to targeted therapies. Science. (2007) 318:287-90. doi: 10.1126/science.1142946

106. Chakravarty D, Pedraza AM, Cotari J, Liu AH, Punko D, Kokroo A, et al. EGFR and PDGFRA co-expression and heterodimerization in glioblastoma tumor sphere lines. Sci Rep. (2017) 7:9043. doi: 10.1038/s41598-01708940-9

107. Nazarenko I, Hede SM, He X, Hedrén A, Thompson J, Lindström MS, et al. PDGF and PDGF receptors in glioma. Ups J Med Sci. (2012) 117:99-112. doi: 10.3109/03009734.2012.665097

108. Frolov A, Evans IM, Li N, Sidlauskas K, Paliashvili K, Lockwood N, et al. Imatinib and Nilotinib increase glioblastoma cell invasion via Ablindependent stimulation of p130Cas and FAK signalling. Sci Rep. (2016) 6:27378. doi: 10.1038/srep27378
109. Pitz MW, Eisenhauer EA, MacNeil MV, Thiessen B, Easaw JC, Macdonald DR, et al. Phase II study of PX-866 in recurrent glioblastoma. Neuro Oncol. (2015) 17:1270-4. doi: 10.1093/neuonc/nou365

110. Kong DS, Song SY, Kim DH, Joo KM, Yoo JS, Koh JS, et al. Prognostic significance of c-Met expression in glioblastomas. Cancer. (2009) 115:140-8. doi: $10.1002 / \mathrm{cncr} .23972$

111. Petterson SA, Dahlrot RH, Hermansen SK, K A Munthe S, Gundesen MT, Wohlleben $\mathrm{H}$, et al. High levels of c-Met is associated with poor prognosis in glioblastoma. J Neurooncol. (2015) 122:517-27. doi: $10.1007 /$ s11060-015-1723-3

Conflict of Interest: The authors declare that the research was conducted in the absence of any commercial or financial relationships that could be construed as a potential conflict of interest.

Copyright (c) 2019 Taylor, Brzozowski and Skelding. This is an open-access article distributed under the terms of the Creative Commons Attribution License (CC BY). The use, distribution or reproduction in other forums is permitted, provided the original author(s) and the copyright owner(s) are credited and that the original publication in this journal is cited, in accordance with accepted academic practice. No use, distribution or reproduction is permitted which does not comply with these terms. 